\title{
An Investigation into Property Variances Between Outer and Inner HDPE Pipe Layers
}

\author{
Wafia GHABECHE*, Kamel CHAOUI** \\ *Mechanics of Materials and Plant Maintenance Research Laboratory (LR3MI), Physics Dept., Badji Mokhtar University \\ of Annaba, P.O. Box 12, Annaba 23052, Algeria. Permanent Researcher at the Industrial Technologies Research Center \\ (CRTI), P.O. Box 64, Cheraga, Algiers 16014; E-mail: ghabechewafia@gmail.com \\ **Mechanics of Materials and Plant Maintenance Research Laboratory (LR3MI), Mechanical Eng. Dept., Badji Mokhtar \\ University of Annaba, P.O. Box 12, Annaba 23052, Algeria. E-mail: chaoui.kam23@gmail.com (corresponding author)
}

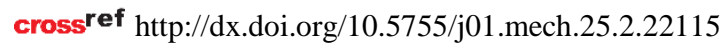

\section{Nomenclature}

$A O$ - antioxidants; $C B$ - \% carbon black; $D S C$ - differencial scanning calorimetry; $E$ - Young's modulus, MPa; HDPE high-density polyethylene; $H S$ - Shore hardness; $I L$ - inner layer; $J_{I C}$ - critical energy release rate, $\mathrm{kJ} / \mathrm{m}^{2} ; K_{I C}$ - fracture toughness, MPa. $\sqrt{ } \mathrm{m} ; \mathrm{La}$ - most probable amorphous layer thickness, nm; $L c$ - most probable crystalline layer thickness, $\mathrm{nm} ; L p \quad$ - long period of the lamellar stacking, nm; MDPE - medium-density polyethylene; $M F I$ - melt flow index; $O D$ - outer diameter, mm; $O L$ - outer layer; $O I T$ - oxidation induction time; $P E$ - polyethylene; $P P$ - polypropylene; $R a$ - arithmetical mean roughness, $\mu \mathrm{m} ; R q$ - root mean square roughness, $\mu \mathrm{m} ; R z$ - average maximum height of the profile, $\mu \mathrm{m} ; S C G$ - slow crack growth, $S D R$ - standard dimension ratio; $X_{c}$ - crystallinity, $\% ; X R D$ - X rays diffraction; $\varepsilon_{f}$ - failure strain, $\% ; \sigma_{f}$ - failure stress, MPa; $\sigma_{y}$ - yield stress, MPa.

\section{Introduction}

At the present time, it is recognized that extrusion processes used to manufacture high performance polyethylene $(P E)$ and polypropylene $(P P)$ pipes induce significant variances in both molecular structure and product morphology [1-5]. As a result, final pipe properties depend on the ultimate processing parameters which are mostly the rate at which heat is removed and the applied pressure during extrusion. Analysis of extruded $P E$ pipe morphology using atomic force microscopy showed that direct contact cooling with water showers resulted in gradual structure changes accompanied with a small orientation [1]. When studying different pipe cooling rates, thermal gradients caused the spherulites to grow from the outer towards the inner layers creating an orientation across the wall and concluding to a lower resistance to slow crack growth $(S C G)[2,3]$. To predict plastic pipe lifetime under SCG mode, it is compulsory to consider the residual stress distribution imparted by the extrusion process [4-7]. The important part of residual stresses lays in the circumferential direction as it is in direct relation with $S C G$ in plastic pipes. Experimentally measured distributions follow most of the times an exponential form with compressive stresses at the outer surface. In the case of $P E$, residual stress magnitude at the pipe bore is around $0.8 \mathrm{MPa}$ which is roughly $40 \%$ lower compared to $P P$ similar measurement. Consequently, different resins can show considerable variations even though extrusion processes are analogous [5, 6].

The aim of the present work is to investigate the mechanical and surface properties of HDPE pipe for the outer and inner layers as they can influence localized stress concentrators and fluid pressure drop. In addition, some structural properties are analyzed to appreciate morphology differences imparted by extrusion on both pipe sides.

\section{Experimental methods}

\subsection{Field observations}

Typical damage forms on the outer surface of $P E$ pipes are illustrated in Fig.1.

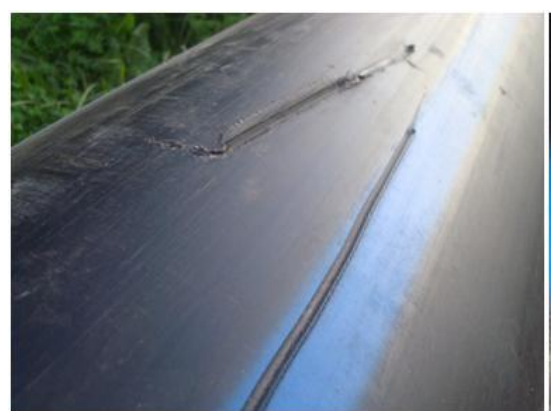

a

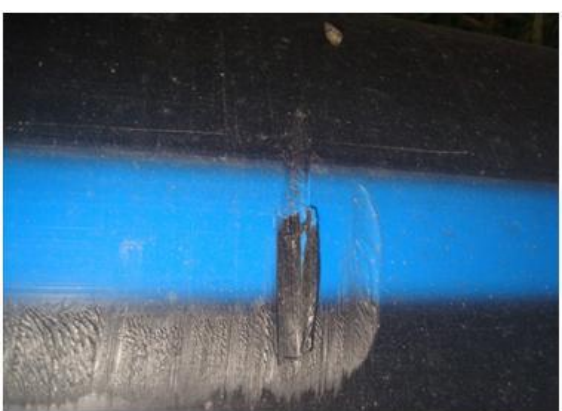

b

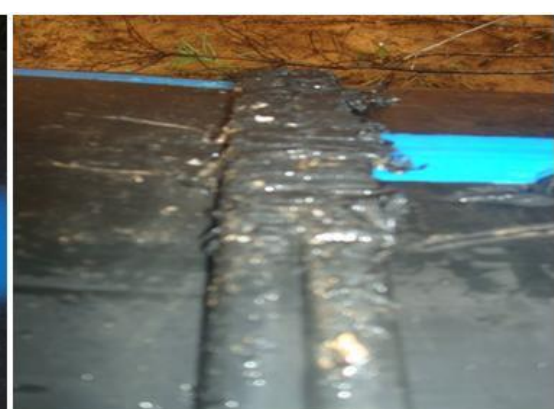

c

Fig. 1 Typical outer skin surface defects: (a) rock impingement longitudinal grooves, (b) scratches and rubs caused by friction and (c) damaged weld bead due to pipe heave against hard road asphalt 
structure. However, field observations show that superficial and even significant damages are induced on the outer surface of the pipes. The scratches shown in Fig. 1 a are usually caused by rock impingements and pipe rubbing on hard and stony soils creating more or less deep notches. These defects may become risky and pernicious during pipe service life as they might grow in the long run as real propagating cracks. It is understood that various scratches or friction marks can be caused by any contact with sufficiently rough or hot objects as revealed in Fig. 1 b. Finally, Fig. $1 \mathrm{c}$ refers to a frequent damage caused to the outside weld seam after pulling on a hard asphalt paved road. These mechanically induced defects can become even more serious if other aggressive environmental effects are added to such adverse conditions.

\subsection{Material and samples preparation}

$P E$ pipe used in this study is the Basell Hostalen CRP 100 black HDPE supplied by CHIALI Company, Sidi BelAbbès, Algeria. It is checked to be free from any surface alteration due to mishandling or unwanted contacts with other objects during transportation. Pipe standard dimension ratio (SDR) and outside diameter are 11 and $200 \mathrm{~mm}$ respectively. Typical properties are shown in Table 1.

Table 1

Selected material properties according to manufacturer technical data sheet

\begin{tabular}{|c|c|}
\hline Density & $\geq 930 \mathrm{~kg} / \mathrm{m}^{3}$ \\
\hline$M F I$ & $0.2-1.4 \mathrm{~g} / 10 \mathrm{~min}$ \\
\hline$\% C B$ & $2-2.5 \%$ \\
\hline$E$ & $0.55-1 \mathrm{GPa}$ \\
\hline$\sigma_{y}$ & $20-30 \mathrm{MPa}$ \\
\hline$\varepsilon_{f}$ & $\geq 350 \%$ \\
\hline$H S$ & $61-67$ \\
\hline$K_{I C}$ & $2-5 \mathrm{MPa} \sqrt{\mathrm{m}}$ \\
\hline$O I T$ & $>20 \mathrm{~min}$ \\
\hline
\end{tabular}

In order to obtain localized mechanical properties, standard tensile specimens are machined directly from the pipe. Each $P E$ pipe section is either turned or bored respectively to get both inner and outer envelopes as shown in Fig. 2.

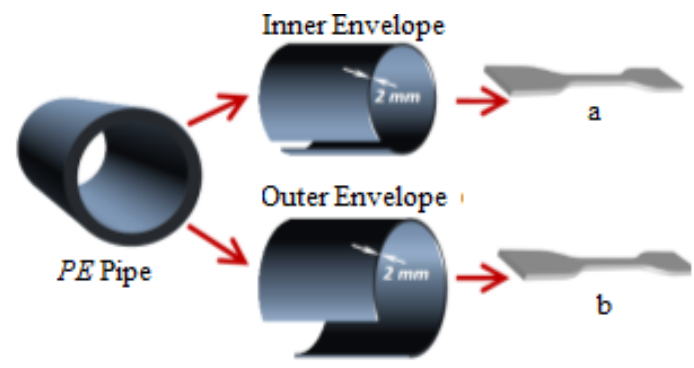

Fig. 2 Standard testing specimen preparation from (a) inner and (b) outer pipe envelopes

One slit envelope can provide from 10 to 15 valid standard test specimens according to the general recommendations of ISO 527 and ASTM D-638. Cutting and slitting are performed using a parallel lathe with an orthogonal tool to avoid damaging pipe surfaces. Standard specimens with a thickness $\leq 4 \mathrm{~mm}$ and a gage width of $6.5 \mathrm{~mm}$ are subjected to monotonic tensile loads using a Zwick-1120 universal testing machine equipped with a $2 \mathrm{kN}$ load cell and an extensometer. The TestXpert software controlled the experimental output data and recorded the information in real time using an RS232 computer interface. All experiments are conducted at ambient laboratory temperature at $50 \mathrm{~mm} / \mathrm{min}$.

Pipe surfaces are analyzed using scanning electron microscopy with magnifications up to 30.000 times. The metallization is performed by depositing a layer of gold. The surface micro-topography is examined by means of 3D Altisurf 500 profilometer from ALTIMET. Data acquisition is completed by scanning with a $3 \mathrm{D}$ reconstruction and regular roughness parameters are instantly provided by Altimap Software, according to current standards. The measuring head is a high resolution Altiprobe white light. Its range lays from 0 to $350 \mu \mathrm{m}$ and uses a working distance of $12 \mathrm{~mm}$ with a resolution of $11 \mathrm{~nm}$. The scanned zone is a $5 \mu \mathrm{m}$ circular spot light at the measurement surface. The device allows scanning a sample surface of $2 \times 2 \mathrm{~mm}^{2}$, with $0.8 \mathrm{~mm}$ cutoff.

The various roughness components are automatically measured and the standard criteria $\left(R_{a}, R_{q}\right.$ and $R_{z}$, as defined by DIN-4768:1990) are calculated based on the following equations:

$$
\begin{aligned}
& R_{a}=\frac{1}{N} \sum_{i=1}^{N}\left|Y_{i}\right| \\
& R_{q}=\sqrt{\frac{1}{N} \sum_{i=1}^{N} Y^{2}} \\
& R_{z}=\frac{1}{5} \sum_{i=1}^{5} Y_{p_{i}}+\frac{1}{5} \sum_{i=1}^{5} Y_{v_{i}},
\end{aligned}
$$

where: $N$ is the number of events (depth or peak); $Y_{i}$ are the deviations from a mean line; $Y_{p i}$ is the highest profile peak and $Y_{v i}$ is the depth of the lowest profile.

Shore hardness measurements were performed using a Mitutoyo durometer Hardmatic (HH-401) based on a statistical protocol for both specimen surfaces. This test is normally the rebound of a spherical calibrated carbide projectile at a determined rate on the material to be tested; the harder the material the higher the rebound. The device measures the ratio of rebound speed compared to the impact speed. Hardness reading is electronically displayed on a screen after recording corresponding signal voltages because of projectile movements. It should be noted that because of specimen curvature, inner surface hardness measurements should be carefully carried out by ensuring the true complete contact of the probe with the plane.

Oxidation induction time is analyzed using a NETZSCH (A 200 PC) differential scanning calorimeter. Samples weighting $15 \mathrm{mg}$ ( $\pm 2 \mathrm{mg}$ ) are taken from each surface and OIT is determined by drawing a tangent to the steepest portion of exothermal curve in agreement with EN 728 AFNOR Norm at $200^{\circ} \mathrm{C}$ in an oxygen flow of $50 \mathrm{~mL} \mathrm{~min}^{-1} \pm$ $10 \%$.

Crystallinity is calculated using different techniques. The XRD spectra are measured using an X'pertPro (PANalytical) X-ray diffractometer. A scan rate of $2 \%$ min at 2000 cycles is performed using $\mathrm{CuK}_{\alpha}$ radiation for a wavelength $\lambda$ equal to $0.154056 \mathrm{~nm}$. A radial scan of Bragg angle versus intensity is obtained with an accuracy of $\pm 0.25^{\circ}$ at the location of the peak. The processing of diffraction patterns is checked with reference to the JCPDS cards (ASTM Pdf $\mathrm{N}^{\circ} 11-834$ ). 
Subsequently, crystallinity is determined using Eq. 2:

$$
X_{C}=\frac{\int_{0}^{\infty} I_{c r}}{\int_{0}^{\infty} I_{a m}+\int_{0}^{\infty} I_{c r}},
$$

where: $I_{c r}$ and $I_{a m}$ are scattering intensities of crystalline and amorphous structures respectively. The mean size of the ordered (crystalline) domains, known also as the long period $L_{p}$, is given by Scherrer Eq. [8]:

$$
\left\langle L_{p}\right\rangle=\frac{K \lambda}{\beta \cos \theta},
$$

where: $K$ is dimensionless shape factor close to unity, $\beta$ is the line broadening at half the maximum intensity (in rad.) and $\theta$ is the Bragg angle.

For DSC measurements, a Mettler TA 3000 device allowing temperature scans from $-170^{\circ} \mathrm{C}$ up to $+600^{\circ} \mathrm{C}$ is used. We have chosen to work on mass samples of $10 \mathrm{mg}$ with a heat rate of $10^{\circ} \mathrm{C} / \mathrm{min}$. Crystallinity is then calculated from Eq. 4:

$$
X_{C}=\frac{\Delta H_{f}}{\Delta H_{0}} \times 100
$$

where: $\Delta H_{f}$ and $\Delta H_{f 0}$ in $(\mathrm{J} / \mathrm{g})$ are respectively the changes in melting enthalpies of the material and the perfectly crystalline $\mathrm{PE}$. The reference value $\Delta H_{f 0}$ is usually taken from literature as $293 \mathrm{~J} / \mathrm{g}$. By means of Gibbs-Thomson expression, the crystallites size is calculated using Eq. 5:

$$
L_{C}=\frac{2 \sigma_{e} T_{m}^{0}}{\Delta H_{f 0}\left(T_{m}^{0}-T_{m}\right)},
$$

where: $\sigma_{e}$ is the surface free energy and $T_{m}{ }^{0}$ is the extrapolated equilibrium melting temperature. These two parameters for $P E$ are $910^{-6} \mathrm{~J} / \mathrm{cm}^{2}$ and $144.85^{\circ} \mathrm{C}$ respectively [4].

For the last method, experimentally measured densities for outer and inner pipe layers according to ISO 1183 are used to compute $X_{c}$ from Eq. 6 :

$$
X_{C}=\frac{\frac{1}{D}+\frac{1}{D_{a m}}}{\frac{1}{D_{a m}}+\frac{1}{D_{c r}}},
$$

where: $D_{c r}$ and $D_{a m}$ are completely crystalline and completely amorphous structure densities respectively. Such data is available in literature [3]; for $P E: 1 / D_{a m}=1.172 \mathrm{~cm}^{3} / \mathrm{g}$ and $1 / D_{c r}=0.996 \mathrm{~cm}^{3} / \mathrm{g}$.

\section{Results and discussion}

\subsection{Mechanical behavior}

Fig. 3 shows the true stress-strain mechanical behavior for both layers. The overall shape is typical for semi-crystalline $P E$ as it reveals a large plastic zone which includes yielding at constant volume and plastic hardening. Although the transition $(B)$ between elastic and plastic behaviors is not explicit as much as necessary for an immediate comparison, it is concluded that the inner layer shows better properties in elastic $(A)$ and plastic $(C)$ zones. It is noted that the inner layer is generally associated with positive residual stresses and a rather crystalline structure with respect to the outer layer (Table 2). This state of structure is a result of the manufacturing extrusion process.

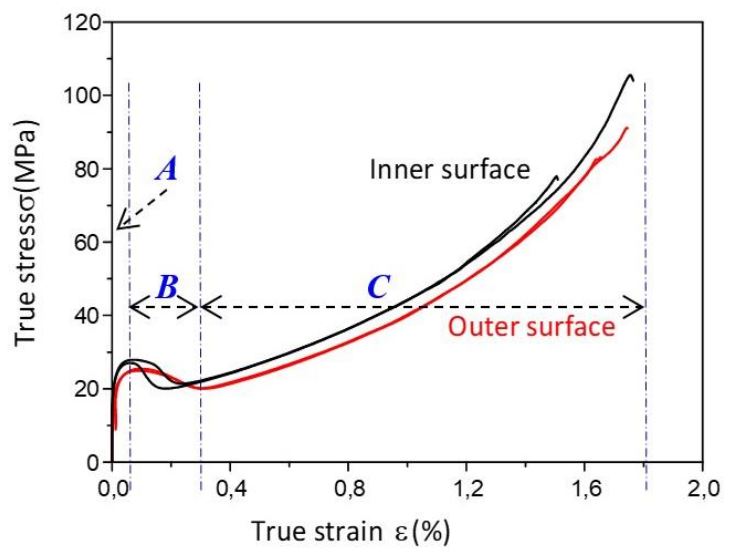

Fig. 3 Typical true $\sigma-\varepsilon$ curves for outer and inner envelopes

Table 2

Key mechanical properties for inner and outer pipe layers

\begin{tabular}{|l|c|c|}
\cline { 2 - 3 } \multicolumn{1}{c|}{} & Inner layer & Outer layer \\
\hline$E ; \mathrm{MPa}$ & $1725.72 \pm 93.25$ & $871.30 \pm 43.40$ \\
\hline$\sigma_{y} ; \mathrm{MPa}$ & $27.42 \pm 0.13$ & $24.61 \pm 0.07$ \\
\hline$\sigma_{f} ; \mathrm{MPa}$ & $102.98 \pm 2.68$ & $81.96 \pm 5.70$ \\
\hline$\varepsilon_{f} ; \%$ & $1.65 \pm 0.11$ & $1.65 \pm 0.05$ \\
\hline \hline$\sigma_{\text {resid. }} P E ; \mathrm{MPa}[5]$ & +1.6 & -4.5 \\
\hline$\sigma_{\text {resid. }} P P ; \mathrm{MPa}[6]$ & +0.9 & -2.4 \\
\hline$J_{I C} ; \mathrm{kJ} / \mathrm{m}^{2}[9]$ & 43.90 & 58.25 \\
\hline
\end{tabular}

It has been found that the inner layer Young's modulus is $1725.72 \mathrm{MPa}$, representing about 1.9 times that of the outer layer. Thus, the following correlations for $E$ and $\sigma_{y}$ can be avowed:

$$
\begin{aligned}
& E^{I L}>E^{O L}, \\
& \sigma_{y}^{I L}>\sigma_{y}^{O L} .
\end{aligned}
$$

The dominance of inner layer mechanical characteristics may also include other properties. For instance; deformation at break is virtually the same in both cases. In order to get an idea about material resistance to crack propagation, it has been shown that the difference between fracture toughness values $\left(J_{I C} ; \mathrm{kJ} / \mathrm{m}^{2}\right)$ for the two layers can reach up to $25 \%$ in favor of the outer layer. Again, the variations are attributed to changes in internal stresses and microstructure $[5,6,9]$.

\subsection{Surface properties}

Inner and outer surface have different morphologies: inner surfaces seem smooth, with small and asymmetric spherulitic texture. It is understood that gradual changes in the morphology are dominating from small asymmetric spherulites to 
randomly nucleated round-shaped ones when going from outer towards inner pipe surface (Figs. 4, a, b). This is confirmed by Trifonova et al. study [1]. However, such texture does not appear in the outer layer, as a result of the cooling conditions (Figs. 4, c, d). Skin effect is associated with extruded plastic products especially for structure as reported in Treselius et al. work [2].

In fact, polymer skin is divided into 3 parts: $(i)$ a nonspherulitic structure, $\sim 20 \mu \mathrm{m}$ thick, is observed for outer surface (Fig. 4, d); (ii) followed with an imperfect spherulitic structure, about $50 \mu \mathrm{m}$ thick; and finally (iii) the normal spherulitic configuration of the bulk material for over $130 \mu \mathrm{m}$. This last structure is essentially observed in the inner layer as it is slowly cooled during manufacturing (Fig. 4, b).

\section{Inner surface}

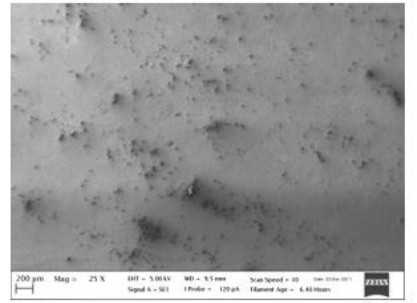

a) $25 \mathrm{X}$

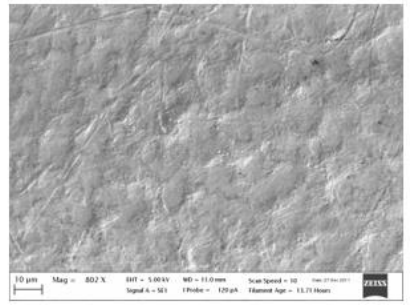

b) $809 \mathrm{X}$
Outer surface

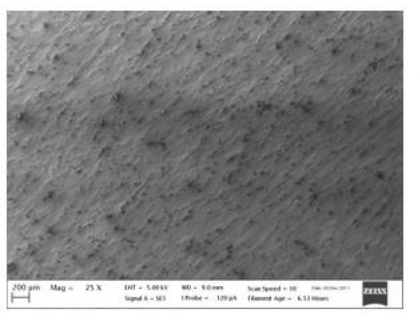

c) $25 X$

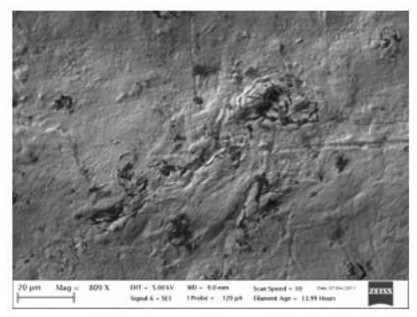

d) $802 \mathrm{X}$
Fig. 4 SEM micrographs for pipe specimens: (a, b) inner surface and (c, d) outer surface

The inner surface is less rough than outer one. This is due to the contact of the pipe with the extrusion die and the rapid cooling achieved by intensive water showers allowing a resulting crimped and irregular surface prints (Fig. 4, d). Higher magnification allowed identifying small-scale structural elements $(\sim 2 \mu \mathrm{m})$ which are possibly related to the spherulitic structure of the bulk material. Relatively small and imperfect spherulites are observed under polarized light microscopy and such structure persists from the bulk towards the inner wall surface [2].

A first hypothesis can be the presence of carbon black species or their agglomerates at both inner and outer surfaces as it can be suggested from Figs. 4, a and c. It can be assumed that $C B$ species have migrated to the surface during the cooling process. Alternatively, another explanation can be related to the initial $C B$ distributions within the raw material which can lead to different fracture modes and surfaces. Literature indicates that although yield properties were similar, the post-yield properties were significantly dissimilar especially when $C B$ distributions are random [10].

In Nie et al. study [4], it is stated that the dissimilar cooling rates across pipe wall surfaces generate a temperature gradient and provoke lamellar orientation along the radial direction. It is also concluded that such conditions lead to the development of the lowest tie-molecules density in the inner wall. Consequently, the resistance of the inner layer to radial SCG becomes poor. Furthermore, cracks are allowed to develop starting at the inner wall of the pipe, through the wall, and then turn aside along the longitudinal direction [4].

Surface topography can explain the differences between inner and outer surface roughness. Fig. 5 illustrates topography and roughness profiles in $\mathrm{X}$ and $\mathrm{Y}$ directions at 2 positions of $H D P E$ pipe. It is observed that inner surface encloses same hollows (Fig. 5, a) while cooling waves are observed on outer surface (Fig. 5, b). In all directions, surface topography presents higher profile peaks and deeper valleys for every evaluation roughness length.

Besides mechanical properties presented in the previous section, both roughness and hardness are more important for the outer layer (Table 3). Indeed, as the formed pipe is leaving the extrusion process, the solidifying melt is at a relatively high temperature. The contact with the inner side of the die influences the state of the resulting surface quality just before cooling. Experimental measurements indicate that the quenched surface develops a roughness greater than that cooled by free convection (internal surface). The positive differences between the two surfaces in terms of $R_{a}, R_{q}$ and $R_{z}$ are $31 \%, 32 \%$ and $41 \%$ respectively.

Table 3

Evolution of roughness and hardness measurements of inner and outer pipe surfaces

\begin{tabular}{|c|c|c|c|}
\cline { 3 - 4 } \multicolumn{2}{c|}{} & Inner surface & Outer surface \\
\hline \multirow{2}{*}{$\begin{array}{c}\text { Roughness } \\
\text { Criteria; } \mu \mathrm{m}\end{array}$} & $R_{a}$ & $0.75 \pm 0.19$ & $1.09 \pm 0.18$ \\
\cline { 2 - 4 } & $R_{q}$ & $0.92 \pm 0.24$ & $1.37 \pm 0.21$ \\
\cline { 2 - 4 } & $R_{z}$ & $4.01 \pm 0.88$ & $6.79 \pm 1.16$ \\
\hline \multicolumn{2}{|c|}{ Shore Hardness } & $48.9 \pm 0,6$ & $60.6 \pm 2.13$ \\
\hline
\end{tabular}

In the same trend, outer layer hardness is much higher than that of the inner layer as the difference reached $19.3 \%$. For absolute roughness and Shore hardness data, it becomes interesting to write down the following correlations:

$$
\begin{aligned}
& R_{a}^{I L}<R_{a}^{O L}, \\
& S H^{I L}<S H^{O L} .
\end{aligned}
$$

It is understood that processing conditions and especially the lamellar flowing of the external surface are responsible for such discrepancies in favor of the outer surface. It should be mentioned that the lower the inner surface roughness the better it is to reduce pressure drop during service.

\subsection{Structure changes}

In this work, the structure is assessed using the two properties represented by the $X_{c}$ for the extent of the amorphous and crystalline parts and the OIT to define the differences in resistance to thermal degradation within the pipe wall. Tables 4 and 5 recapitulate measured and calculated results regarding $X_{c}, O I T$ and some morphological properties related to semi-crystalline polymers. In terms of crystallinity, it is found that the inner side exhibits constantly higher values whatever is the measuring method. Such result can be used as a worthy and plausible explanation for the better mechanical properties of the inner layer as indicated previously in Table 2. 
a) Inner surface

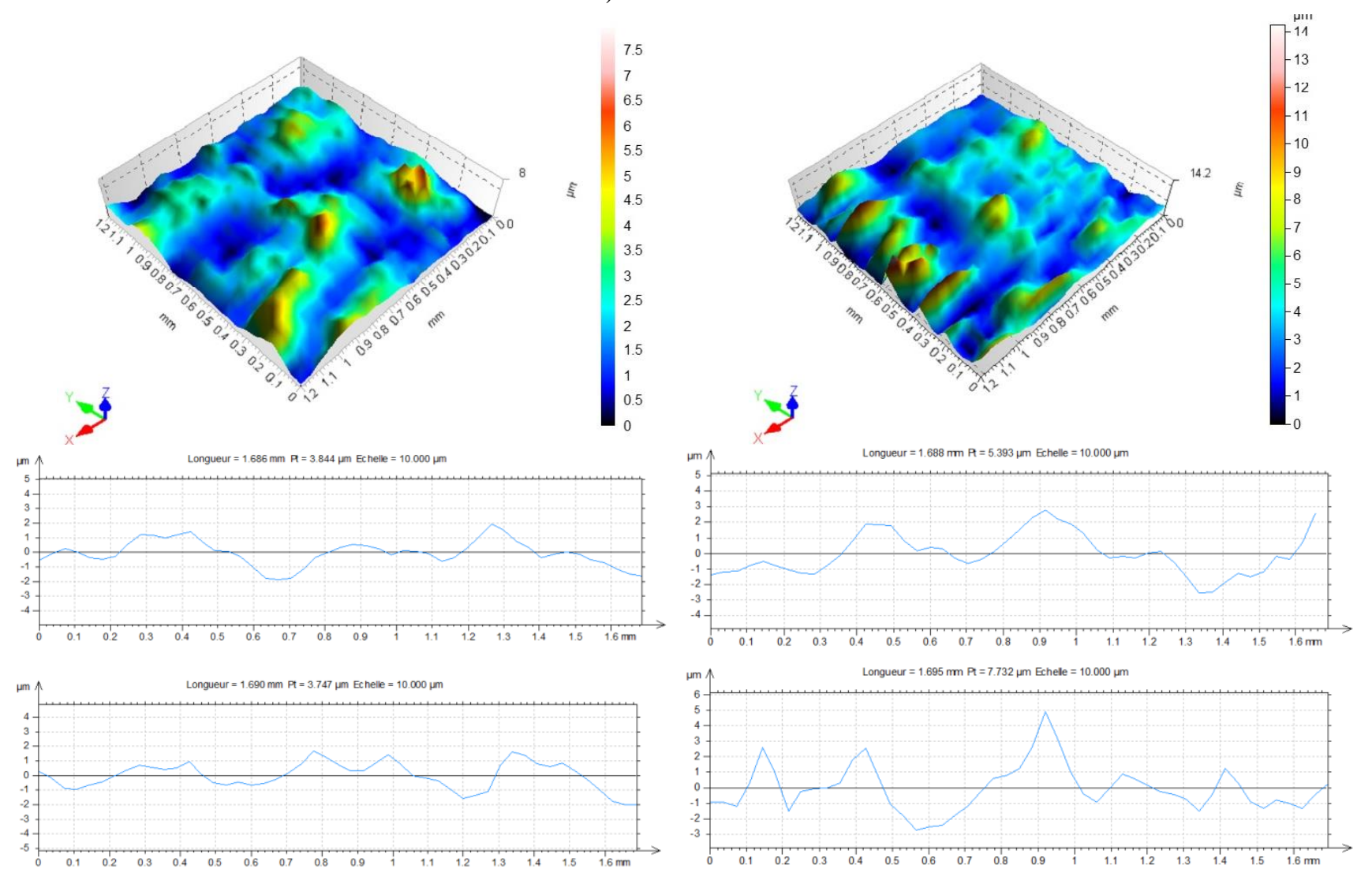

b) Outer surface
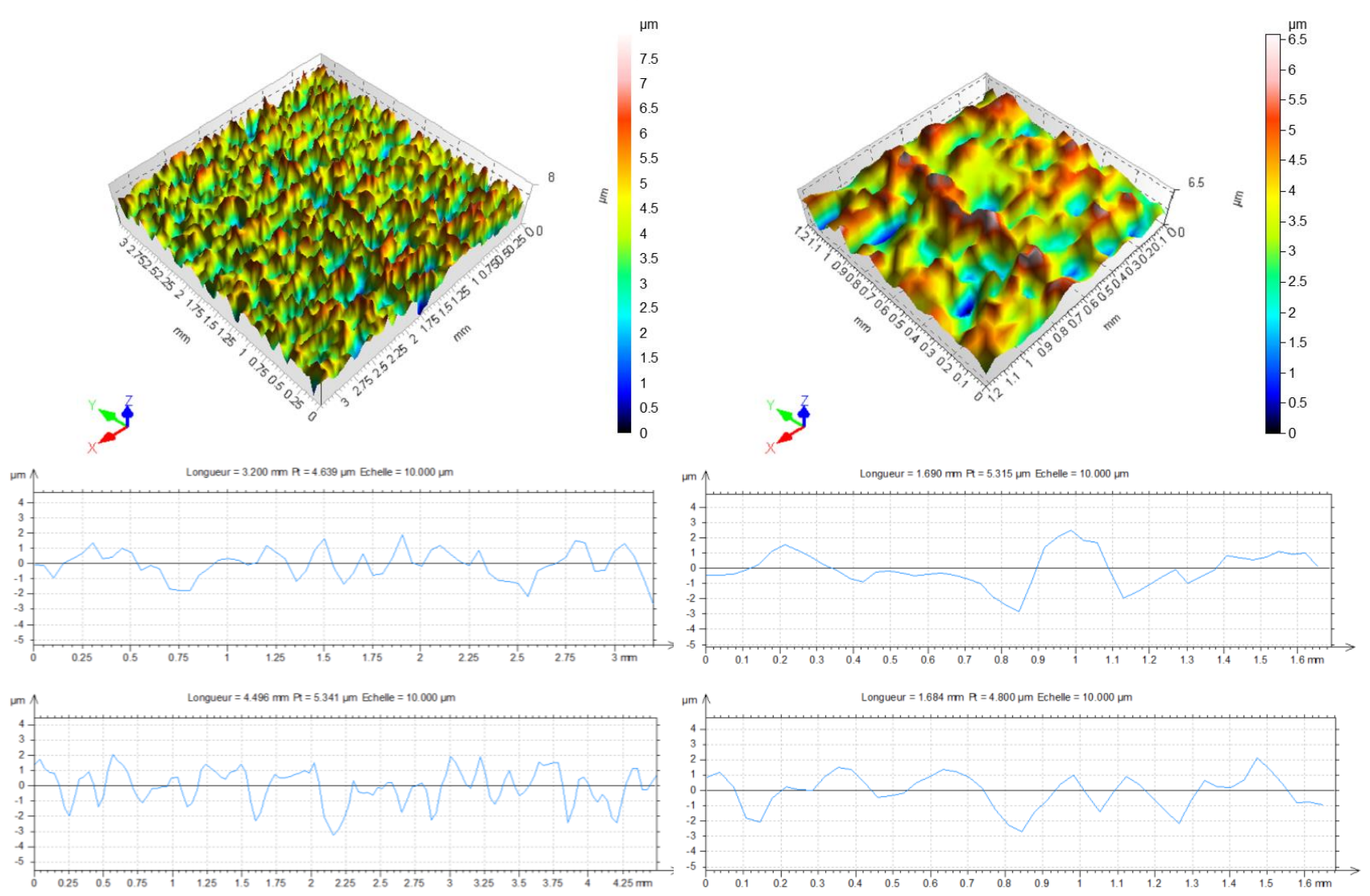

Fig. 5 Micro-topography and roughness profiles in $X$ and $Y$ directions at 2 positions of $H D P E$ pipe

However, such rationalization is not appropriate for the critical energy release rate $\left(J_{I C}\right)$ which is most probably influenced by the enforced residual stress state. Fortunately, higher $J_{I C}$ at the outer layer is beneficial for pipes as it would indicate that stress concentrators and surface defects are unlikely to initiate or enhance catastrophic crack propagation conditions.

The measured $X_{c}$ values are shown in Table 4 for 
both cases. The change is as high as $25.6 \%$ based on DSC method which largely used in industry. The lowest and highest crystallinity values were given by XRD and DSC methods.

Table 4

Crystallinity changes for outer and inner pipe surfaces using different measuring methods

\begin{tabular}{|c|c|c|c|}
\cline { 2 - 4 } \multicolumn{1}{c|}{} & Method & Inner layer & Outer layer \\
\hline \multirow{3}{*}{$\boldsymbol{X}_{\boldsymbol{c}} ; \boldsymbol{\%}$} & XRD & 61.31 & 51.55 \\
\cline { 2 - 4 } & DSC & $\mathbf{6 4 . 2 6}$ & $\mathbf{4 7 . 7 9}$ \\
\cline { 2 - 4 } & Density & 61.54 & 48.42 \\
\hline
\end{tabular}

The largest variations among the 3 methods for $X_{c}$ are $7.3 \%$ and $4.5 \%$ respectively for outer and inner surfaces. The change is as high as $25.6 \%$ based on DSC method which largely used in industry. The lowest and highest crystallinity values were given by XRD and DSC methods. The largest variations among the 3 methods for $X_{c}$ are $7.3 \%$ and $4.5 \%$ respectively for outer and inner surfaces. At this step, it is possible to write the following relationship based on crystallinity measurements for outer and inner pipe surfaces:

$$
X_{c}^{I L}>X_{c}^{O L}
$$

Generally, pipe manufacturing industry utilizes antioxidants $(A O)$ to reduce the phenomenon of oxidation during storage, handling and service. These additives can act locally or migrate through the resin to minimize and/or eliminate potential oxidants which can cause irreversible damage to the pipe basic structure. Frequently used $A O$ for HDPE pipes processing stabilization are alkyl phenols, phenolic primary components, and hydrolytically stable organo-phosphites [11].

In terms of OIT and morphology, the measured and/or computed parameters are presented in Table 5 .

Table 5

OIT and morphology parameters

\begin{tabular}{|c|c|c|c|c|}
\cline { 2 - 5 } \multicolumn{1}{c|}{} & Method & Inner layer & Outer layer & Ref. \\
\hline OIT; min & DSC & $\mathbf{2 2 . 7}$ & $\mathbf{2 6 . 5}$ & {$[12]$} \\
\hline$L_{p} ; \mathrm{nm}$ & XRD & 14.4 & 15.6 & $*$ \\
\hline \multirow{3}{*}{$L_{c} ; \mathrm{nm}$} & DSC & 13.3 & 13.6 & $*$ \\
\cline { 2 - 5 } & XRD & 17.1 & 13.8 & \multirow{2}{*}{ X } \\
\cline { 2 - 5 } & DSC & 14.8 & 13.8 & \\
\cline { 2 - 5 } & DSC & 22.3 & 18.3 & {$[8]$} \\
\hline$L_{a} ; \mathrm{nm}$ & deduced & 1.1 & 2.0 & $*$ \\
*This study
\end{tabular}

It is worth noting that both OIT values are above the one provided by the manufacturer (Table 1). It is worth noting that $O I T$ values from both pipe sides are above the one provided by the manufacturer (Table 1). It is found that outer surface OIT is roughly $14 \%$ higher compared to that of inner surface (Table 5). Consequently, it is acknowledged that the outer layer is much more predisposed to resist thermal degradation than the inner layer although it has undergone rapid cooling just after extrusion. This finding is in good agreement with critical energy release rate, Shore hardness and published $O I T$ results (Tables 2, 3 and 6). In addition, the calculated crystalline $(L c)$ and amorphous $(L a)$ layer thicknesses, respectively designated by $L c$ and $L a$, are found to be much significant at the outer surface layer compared to the inner one. These results are also corroborated from other studies $[4,9]$. The summation of $L c$ and $L a$ is known as the long period of the lamellar stacking $(L p)$ which is also a higher parameter for the outer surface.

Table 6

Comparison of $X_{c}$ and $O I T$ measurements from diverse studies

\begin{tabular}{|c|c|c|c|c|}
\hline Pipe Dimensions & $\begin{array}{c}\text { Layer } \\
\text { position }\end{array}$ & $X_{c} ; \%$ & $O I T ; \min$. & Ref. \\
\hline \multirow{2}{*}{$\begin{array}{l}\text { Self-reinforced } \\
\text { HDPE, OD=63mm, } \\
\text { SDR } 17\end{array}$} & IL & 88 & - & \multirow{2}{*}{ [7] } \\
\hline & OL & 70 & - & \\
\hline \multirow{2}{*}{$\begin{array}{l}\text { PE-100, OD=200mm, } \\
\text { SDR } 11\end{array}$} & IL & 46 & - & \multirow{2}{*}{ [9] } \\
\hline & $\mathrm{OL}$ & 38 & - & \\
\hline \multirow{2}{*}{$\begin{array}{l}\text { PE-100, OD=200mm, } \\
\text { SDR } 11\end{array}$} & IL & 61.3 & 22.7 & \multirow{2}{*}[12]{} \\
\hline & OL & 51.5 & 26.5 & \\
\hline \multirow{2}{*}{$\begin{array}{l}\text { MDPE-80, } \\
\text { OD=90mm, SDR } 11\end{array}$} & IL & 45.4 & 93.5 & \multirow{2}{*}{ [13] } \\
\hline & OL & 42.6 & 84.9 & \\
\hline \multirow{2}{*}{$\begin{array}{l}\text { PE-100, OD }=50 \mathrm{~mm} \text {, } \\
\text { SDR 11; DSC and IR }\end{array}$} & IL & 67.5 & 63 & \multirow{4}{*}[14]{} \\
\hline & $\mathrm{OL}$ & 61.0 & 68 & \\
\hline \multirow{2}{*}{$\begin{array}{l}\text { PE-80, OD=50mm, } \\
\text { SDR 11; DSC and IR }\end{array}$} & IL & 65.5 & 105 & \\
\hline & OL & 58.5 & 115 & \\
\hline
\end{tabular}

During the cooling operations associated with the extrusion process, quenched outer surface with water baths assists fixing $A O$ in the closest pipe layers. On the opposite side, atmospheric oxygen surrounding inner surface layers consumes the available $A O$ all through sluggish open air cooling. It has been shown that slow cooling of the inner pipe surface leads to the formation of a low concentration of tie molecules in the beneath layer. As a result, the material exhibits a poorer resistance to crack propagation compared to the outer pipe layer [4]. Although pipe suppliers do not reveal anti-oxidation type used in most fabricated products, the measurement of $O I T$ gives valuable information about $A O$ concentration. That is why it is considered as a good appraisal of pipe resistance to oxidation occurrence.

On the other hand, residual stresses effect on pipe service life is furthermore decisive. Negative (or compressive) residual stresses support an advantageous outcome as they help reducing localized service loads; however, positive residual stresses (or tensile) proceed unfavorably since they accentuate applied stresses [10]. The main result of this step can be expressed in the following relationship using OIT as measured from DSC:

$$
O I T^{I L}<O I T^{O L}
$$

In order to comfort the obtained results, a literature survey is done for crystallinity and oxidation induction time associated with PE pipes. The change in $X_{c}$ between outer and inner surfaces attained the $15 \%$ difference and it can even reach higher values. Table 6 summarizes some results of $X_{c}$ and OIT from literature. Indeed, these findings are in agreement with the conclusion that $X_{c}$ is increasing across the pipe wall from the outer towards the inner surface.

A similar trend is observed for OIT measurements as compiled also in Table 6 . It is noted that OIT differences range from $9 \%$ up to $27 \%$ in favor of the outer surface. However, one exception is found in the work of Talhi et al. as the difference is $\sim 10 \%$ but in favor of the inner surface for 
a CB pigmented MDPE pipe [13]. For the case of dug out pipes, the reported cases from literature indicate that $X_{c}$ evolved practically towards a similar level with a difference between outer and inner surface approaching the $\sim 12 \%$. The gas pipe kept a high OIT value while the water pipe indicates that it probably underwent some degradation as its OIT dropped to a low level [14].

Critical contaminant migration, issued from plastic pipe additives (i.e. $A O$, stabilizers, lubricants, and fillers) is well reviewed in literature [11]. Although, such additives are commonly incorporated to improve HDPE pipes properties (i.e. strength, resistance to degradation, flexibility, color...); they can constitute a major risk for surface alteration and transported fluids. Indeed, outer surface roughness can reveal adverse consequences because of uncontrolled environmental chemical species and pipe landfill friction causing pipe damage followed by fluid leakage.

Also, PE welding operations are concerned because it is necessary to eliminate surface irregularities mechanically or chemically before proceeding to the weld. For internal surface, the most serious problem remains the dissipative friction between fluid flow and the rigid inner pipe wall contributing to substantial pressure drops and pipe vibrations.

\section{Conclusions}

Studying outer and inner pipe surface properties presents a major importance for fluids in interaction with plastic pipe transportation networks. Associating outer and inner pipe layers made it possible to bond surface and adjacent structure properties away from the bulk.

This research work allows to draw the following conclusions:

1. The adopted experimental method involving inward and outward machining allowed accessing mechanical and morphological properties of inner and outer surface layers of an extruded HDPE pipe.

2. It is found that stress-strain curves are similar for both layers. Howeve, the inner layer exhibits higher mechanical properties because of the manufacturing process which engenders compressive residual stresses and higher oxidation industion times.

3. Surface quality evaluation indicates that the diehardened pipe face develops an $R z$ roughness limit $41 \%$ higher than that of inner surface. Meanwhile, Shore hardness follows the same tendency, showing an increase of $19.3 \%$ in favor of the external surface.

4. The methods employed for crystallinity assessment provide acceptable measurements (differences < 8\%). This property is found to be in favor of the internal surface just like mechanical properties. This is justified by the slow convection cooling of the inner pipe face.

5. The observed OIT result for the outer surface layer is $14 \%$ higher than that of the inner one. This is in agreement with the critical energy release rate measurements and the parameters measuring mutually crystalline and amorphous contributions for HDPE microstructure.

\section{Acknowledgements}

The authors would like to thank SONELGAZ, STMP CHIALI and TUB-O-GAZ Companies for providing specimens and sharing plastic pipe data. Machining operation were accomplished at Technological Hall of Guelma University (Algeria). Fruitful discussions with LR3MI laboratory members are highly appreciated.

\section{References}

1. Trifonova, D.; Drouillon, P.; GhanemA.; Vancso, G. J. 1997. Morphology of extruded high-density polyethylene pipes studied by atomic force microscopy, J. Applied Polymer Science 66: 515 - 523.

http://www3.interscience.wiley.com/journal/43777.

2. Terselius, B.; Gedde, U. W.; Jansson, J. 1982. Structure and morphology of thermally oxidized high density polyethylene pipes, Polymer Engineering and Science 22 (7): 422-431. https://doi.org/10.1002/pen.760220706.

3. Hoffman, J. D.; Miller, R. L. 1997. Kinetics of crystallization from the melt and chain folding in polyethylene fractions revisited: theory and experiment, Polymer 38 (13): 3151. 3212. https://doi.org/10.1016/S0032-3861(97)00071-2.

4. Nie, M.; Wang, Q.; Bing-Bai, S.; Li, Z.; Huang, A. 2014. The formation and evolution of the hierarchical structure of polyethylene pipe during extrusion processing, J. Macromolecular Science: Part B, Physics 53: 205-216.

http://www.tandfonline.com/loi/lmsb20.

5. Poduska, J., Kucera, J., Hutar, P., Sevcik, M., Krivanek, J., Sadilek, J., Nahlik, L. 2014. Residual stress distribution in extruded polypropylene pipes, Polymer Testing 40: 88-98.

http://dx.doi.org/10.1016/j.polymertesting.2014.08.006.

6. Poduska, J., Hutar, P., Kucera, J., Frank, A., Sadilek, J., Pinter, G., Nahlik, L. 2016. Residual stress in polyethylene pipes. Polymer Testing 54: 288-295.

http://dx.doi.org/10.1016/j.polymertesting.2016.07.017.

7. Long, J.; Kaizhi, S.; Jiliang, J.; Qing, G. 1998. A mandrel-rotating die to produce high-hoop strength HDPE pipe by self-reinforcement, J. Applied Polymer Science 69: 323-328.

https://doi.org/10.1002/(SICI)1097-

4628(19980711)69:2<323::AID-APP13>3.0.CO;2-X.

8. Le Clerc, C. 2006. Mécanismes microstructuraux impliqués dans la fatigue des fibres thermoplastiques, Thesis, Ecole des Mines de Paris, 289 p. https://pastel.archives-ouvertes.fr/tel-00164759.

9. Hamlaoui, N.; Bendjeddou, O.; Chaoui, K. 2015. Contribution à l'étude expérimentale de l'énergie de rupture à travers la paroi d'un tube de gaz en HDPE-100, $22^{\text {nd }} C F M, A F M$, Lyon, France.

http://documents.irevues.inist.fr/handle/2042/57792.

10. Deveci, S.; Preschilla, N.; Eryigit, B. 2018. Effect of carbon black distribution on polyethylene pipes, Proceedings, $19^{\text {th }}$ Plastic Pipes Conference, PPXIX, September 24-26, Las Vegas, Nevada.

https://www.researchgate.net/publication/328518186.

11. Whelton, A. J.; Nguyen, T. 2013. Critical contaminant migration from polymeric pipes used in buried potable water distribution systems: A Review, 43:679-751.Critical Reviews in Environmental Science and Technology 43:679-751.

https://doi.org/10.1080/10643389.2011.627005. 
12. Ghabeche, W.; Alimi, L.; Chaoui, K. 2015. Degradation of plastic pipe surfaces in contact with an aggressive acidic environment, Energy Procedia 74: 351-364. https://doi.org/10.1016/j.egypro.2015.07.625.

13. Talhi, F.Z.; Benaniba, M.T.; Belhaneche-Bensemra, N.; Massardier, V. 2017. Comparison of material properties in butt welds of used and unused polyethylene pipes for natural gas distribution, J. Polymer Engineering 37(3): 279-285. https://doi.org/10.1515/polyeng-2016-0015.

14. Maria, R.; Rode, K.; Schuster, T.; Geertz, G.; Malz, F.; Sanoria, A.; Oehler H.; Brüll, R.; Wenzel, M.; Engelsing, K.; Bastian, M.; Brendlé, E. 2015. Ageing study of different types of long-term pressure tested PE pipes by IR-microscopy, Polymer 61: 131-139.

https://doi.org/10.1016/j.polymer.2015.01.062.

\section{W. Ghabeche, K. Chaoui}

\section{AN INVESTIGATION INTO PROPERTY VARIANCES BETWEEN OUTER AND INNER HDPE PIPE LAYERS}

S u m m a r y

Many studies devoted to plastic piping investigated mechanical properties as suggested by technical standards; however very few of them were designed for surface roughness and hardness analyses in relation to microstructure. The objective of this research is to establish property differences between inner and outer surface layers of a polyethylene pipe. Machined specimens are prepared from both sides of a pipe and subjected to mechanical testing, roughness and hardness measurements. It is found that local mechanical properties are in favor of the inner layer since the fabrication process produces residual stresses and structural variations. On the other hand, the outer die-hardened pipe face develops high roughness and Shore hardness values. All methods used to obtain crystallinity provided acceptable measurements and they indicated that the inner pipe layer is more crystalline because of slow cooling. Finally, it is shown that oxidation induction time results are $14 \%$ in favor of the outer surface layer. This indicates that the inner layer is more vulnerable to thermal degradation compared to the outer one. Such conclusions are meant to improve the understanding of plastic pipe behavior under mutual external and internal frictional environmental effects during service conditions.

Keywords: polyethylene pipe, stress-strain behavior, surface roughness, hardness, crystallinity, oxidation induction time.

Received December 03, 2018

Accepted April 24, 2019 